\title{
Acknowledgment to reviewers of Journal of Smart Environments and Green Computing in 2021
}

\author{
JSEGC Editorial Office \\ JSEGC Editorial Office, Alhambra, CA 91801, USA. \\ Correspondence to: JSEGC Editorial Office, 245 E Main Street Ste 107, Alhambra, CA 91801, USA. \\ E-mail: editorial@segcjournal.com
}

How to cite this article: JSEGC Editorial Office. Acknowledgment to reviewers of Journal of Smart Environments and Green

Computing in 2021. J Smart Environ Green Comput 2022;2:1-2. https://dx.doi.org/10.20517/jsegc.2022.01

Received: 28 Jan 2022 Accepted: 29 Jan 2022 Published: 29 Jan 2022

Academic Editor: Witold Pedrycz Copy Editor: Xi-Jun Chen Production Editor: Xi-Jun Chen

Rigorous peer review is the corner-stone of high-quality academic publishing. The editors of Journal of Smart Environments and Green Computing (JSEGC) would like to express their sincere gratitude to the following reviewers for their precious time and dedication, regardless of whether the papers were finally published in 2021 [Table 1].

Table 1. The reviewers in 2021

\begin{tabular}{lll}
\hline Name & & \\
\hline Alberto Sillitti & Javier Fernandez & Patricia Melin \\
Allel Hadjali & Jie Lu & Qiang He \\
Chao Chen & Jorge Santos & Radu-Emil Precup \\
Chunsheng Zhu & Juan Antonio Morente-Molinera & Ralf Gente \\
Dalia Streimikiene & Karel Charvat & Ronghu Chi \\
David Trafimow & Lei Pan & Ruben Gonzalez Crespo \\
Deepak Gupta & Leijiao Ge & Sangbing Tsai \\
Domenico Rosaci & Lin Wang & Shaojian Qu \\
Ella Kolkowska & Manuel Jesús Cobo & Silvio Simani \\
Elpiniki Papageorgiou & Matt Ellis & Simon Shen \\
Fabio Arena & Meng-Kun Liu & Wei Zhou \\
Giuseppe Fenza & Michał Bereta & Xingli Wu \\
Hamid Reza Karimi & Miguel Melgarejo & Yongming Han \\
Hamido Fujita & Miroslav HUDEC & Zenonas Turskis \\
Humberto Bustince & Oscar Castillo & \\
\hline
\end{tabular}
adaptation, distribution and reproduction in any medium or format, for any purpose, even commercially, as long as you give appropriate credit to the original author(s) and the source, provide a link to the Creative Commons license, and indicate if changes were made. 


\section{DECLARATIONS}

Authors' contributions

Writing and revision of the article and approved the final version: JSEGC Editorial Office

Availability of data and materials

Not applicable.

\section{Financial support and sponsorship}

None.

\section{Conflicts of interest}

The author declared that there are no conflicts of interest.

\section{Ethical approval and consent to participate}

Not applicable.

\section{Consent for publication}

Not applicable.

\section{Copyright}

(c) The Author(s) 2022. 